\title{
Effects of short-chain fructooligosaccharides on growth performance of preruminant veal calves
}

\author{
E. Grand, ${ }^{*}$ F. Respondek, ${ }^{* 1}$ C. Martineau, $\dagger$ J. Detilleux, $\ddagger$ and G. Bertrand $†$ \\ *Tereos Syral, 67390 Marckolsheim, France \\ †Institut de l'Elevage, 35652 Le Rheu Cedex, France \\ †Department of Animal Production, Faculty of Veterinary Medicine, Liège University, 4000 Liège, Belgium
}

\section{ABSTRACT}

This study was conducted to evaluate the effects of 2 different daily doses of short-chain fructooligosaccharides (scFOS), a prebiotic ingredient, added to a calf milk replacer on growth performance, carcass characteristics, and fecal concentrations of short-chain fatty acids of preruminant veal calves. In total, 112 male Prim'Holstein calves, between 8 and $10 \mathrm{~d}$ of age, were randomized in this study according to their body weight and were bred until the age of $168 \mathrm{~d}$. They were fed a calf milk replacer containing $5 \%$ soluble wheat proteins as well as cereal-based pellets, the composition of which was adapted to cover the needs of the animals throughout the study. After 2 wk of adaptation, the calf milk replacer was supplemented or not supplemented with a daily dose of 3 or $6 \mathrm{~g}$ of scFOS. Growth performance of calves, as measured by body weight, cold carcass weight, feed intake, average daily gain, and feed conversion ratio, was recorded and feces samples were taken to evaluate short-chain fatty acid concentrations. The inclusion of wheat proteins in milk replacer did not negatively affect the growth performance of calves in comparison with general standards. The addition of scFOS in the milk reduced the feed conversion ratio of veal calves in a dose-dependent manner and tended to increase the carcass weight. A general trend was observed for an increased production of total shortchain fatty acids in time, but scFOS decreased acetate proportion to the benefit of butyrate proportion. These data suggest that inclusion of scFOS in the calf milk replacer allowed the growth performance of preruminant calves to be enhanced, possibly via a modification of the activities of microbial fermentation.

Key words: veal calf, growth performance, prebiotic, fructooligosaccharide

Received September 19, 2011.

Accepted October 10, 2012.

${ }^{1}$ Corresponding author: frederique.respondek@tereos.com

\section{INTRODUCTION}

Short-chain fructooligosaccharides (scFOS) are soluble fibers naturally found in vegetables, such as onion, garlic, or wheat. They can also be produced by the transfructosylation of sucrose. Short-chain fructooligosaccharides are composed of a mixture of oligosaccharides consisting of glucose linked to fructose units by $\beta-(1,2)$ links that are not digestible by human enzymes but can be fermented by some strains of Bifidobacterium and Lactobacillus in the large intestine of humans (Roberfroid et al., 2010) and animals (Howard et al., 1995; Swanson et al., 2002a; Xu et al., 2003), including veal calves (Bunce et al., 1995; Philippeau et al., 2010). According to Gibson et al. (2004), scFOS are recognized to have prebiotic properties: (1) they are resistant to gastric acidity, to hydrolysis by mammalian enzymes, and to gastrointestinal absorption; and (2) they are fermented by intestinal bacteria; (3) thus, they selectively stimulate the growth, activity, or both of bacteria associated with health and well-being.

As shown in veal calves and in other animal species, by modulating the gut microbiota, scFOS can enhance the bacterial production of short-chain FA (SCFA) in the large intestine. Cecal and colonic cells can use these fermentation products, especially butyrate, as an energy source, leading to an improved mucosal structure. In piglets, dietary supplementation with scFOS has been shown to increase villus height and crypt depth in the large intestine (Howard et al., 1995; Spencer et al., 1997; Tsukahara et al., 2003). Possibly linked to the selectivity of the fermentation of scFOS in the large intestine, scFOS may improve the zootechnical performance of commercial animal species such as pigs or broilers (Howard et al., 1999; Xu et al., 2003, 2005). In veal calves fed a high quantity of lactose, a short-term dietary supplementation with scFOS enhanced ADG and feed conversion ratio (FCR; Kaufhold et al., 2000).

The objectives of this experiment were to evaluate, during the whole period of rearing, the effects of 2 different daily doses of scFOS added to a calf milk replacer (CMR) containing wheat proteins on growth 
Table 1. Composition of the basal calf milk replacer

\begin{tabular}{|c|c|c|c|}
\hline Item & Starter feed (d 8 to 36$)$ & Grower feed (d 37 to 92$)$ & Finisher feed (d 93 to 168 ) \\
\hline Whey & 52.7 & 48.2 & 44.3 \\
\hline Whey protein concentrate PS35 & 15.5 & 18.7 & 14.2 \\
\hline Wheat protein hydrolysate ${ }^{1}$ & 5.2 & 6.0 & 5.7 \\
\hline Copra & 4.9 & 4.4 & 4.1 \\
\hline Lard & 4.9 & 7.0 & 5.4 \\
\hline Palm & 1.1 & - & - \\
\hline Premix & $1.0^{2}$ & $1.0^{2}$ & $1.0^{2}$ \\
\hline Soy & 0.5 & - & - \\
\hline Rapeseed & 0.1 & - & - \\
\hline Calcium carbonate & 0.4 & 0.5 & 0.7 \\
\hline Lysine & 0.4 & 0.4 & 0.4 \\
\hline Monopotassium phosphate & 0.2 & - & - \\
\hline Crude fat & 17.3 & 18.5 & 19.0 \\
\hline Ash & 7.1 & 6.6 & 6.5 \\
\hline $\mathrm{CP}$ & 19.56 & 20.60 & 19.45 \\
\hline Lysine & 1.53 & 1.65 & 1.57 \\
\hline Methionine + cysteine & 0.85 & 0.90 & 0.85 \\
\hline Proteins from dairy products & 11.73 & 12.35 & 11.68 \\
\hline Proteins from vegetable products & 7.83 & 8.24 & 7.77 \\
\hline Digestible energy, $\mathrm{kcal} / \mathrm{kg}$ & 4,444 & 4,546 & 4,547 \\
\hline
\end{tabular}

${ }^{1}$ Solpro 508 (Syral Belgium NV, Aalst, Belgium).

${ }^{2}$ Premixes were different for each period. The starter feed did not contain lysine.

performances, carcass characteristics, and fecal concentrations of SCFA of veal calves.

\section{MATERIALS AND METHODS}

The present experiment complied with French ethics laws and was conducted under the direction of $\mathrm{G}$. Bertrand from Institut de l'Elevage (Le Rheu, France).

\section{Animals and Diets}

A total of 112 male Prim'Holstein calves, between 8 and $10 \mathrm{~d}$ of age, were used in this experiment. A few days after their arrival, the animals were allocated to 1 of 3 groups according to their BW ( $\mathrm{n}=36$ in the control group, and $n=38$ in the other 2 groups). Animals were fed a CMR, without skim milk but containing soluble hydrolyzed wheat proteins (Solpro 508, Syral Belgium NV, Aalst, Belgium), given in buckets, twice a day during the entire study. After 2 wk of feeding, the CMR was supplemented or not supplemented with an equivalent dose of 3 or $6 \mathrm{~g} / \mathrm{d}$ of scFOS (Profeed P95, $95 \%$ of scFOS with a degree of polymerization between 3 and 5; Beghin Meiji, Marckolsheim, France) immediately before distribution to the animals. The composition of the basal milk replacer is given in Table 1 .
Animals also received solid feeds under the form of cereal-based pellets, once a day within $1 \mathrm{~h}$ after the morning CMR feeding. The composition of the solid feed was adapted to the requirements of the animals throughout the study. From d 8 to 36 of life, the solid feed (starter feed) was distributed at the level of 20 to $50 \mathrm{~g} / \mathrm{d}$ per calf; from d 37 to 92,60 to $160 \mathrm{~g}$ of the grower feed was offered per day; and from d 93 to the end of the experiment (d 168) animals received 160 to $250 \mathrm{~g}$ of the finisher feed per day. A transition period lasting $6 \mathrm{~d}$ between each type of feed was respected.

\section{Measurements of Growth Performance and Health Records}

All calves were weighed at the beginning of the study (d 8; equivalent to $8 \mathrm{~d}$ of age), at d 43, 64, 92, 120, and the day before slaughter (d 167). Feed intake was recorded during each feeding period of the study (growing period: d 8 to 92; finishing period: d 93 to 168). From these data, ADG and FCR were calculated.

At the end of the study (d 168), animals were stunned approximately $30 \mathrm{~s}$ before slaughter and exsanguination. The cold carcass weight, defined as the weight of the animal after bleeding and removal of the viscera, feet, head, hide, and tail, was recorded. 
All carcasses were evaluated on the basis of their color, conformation, and fatness. These evaluations were made according to French standards (OFIVAL, 1976). Regarding the degree of fatness, the scale ranged from 1 (lean carcass) to 5 (very fatty carcass). The carcass color scale ranged from 1 (white) to 4 (red), and the conformation was evaluated by the EUROP standard ( $\mathrm{E}=$ excellent, and $\mathrm{P}=$ degraded conformation, with intermediate levels of classification). In this study, numerical values were assigned to the conformation observed: carcasses that were scored U obtained a grade of 15 , and carcasses scored $\mathrm{P}$ had a grade of 4 , with intermediate grades.

Mortality was recorded daily. The number of days of individual treatment per animal for diarrhea and respiratory diseases was recorded during the entire study period.

\section{Samples Collection and Analysis}

Fecal matter was collected on d 22, 36, and 50 directly from the rectum of calves within $2 \mathrm{~h}$ after the morning CMR feeding. Homogenized and filtrated $(100-\mu \mathrm{m})$ samples $(5 \mathrm{~g})$ were kept frozen until analysis of SCFA. Acetate, propionate, and butyrate concentrations and total SCFA concentrations (total SCFA: acetate, propionate, butyrate, isobutyrate, valerate, and isovalerate) were determined by gas chromatography according to the method of Jouany (1982). The proportions of the main SCFA (acetate, propionate, and butyrate) were calculated by dividing the concentration of this SCFA by the sum of the 3 others.

Blood samples were collected in heparinized tubes upon arrival of the animals (d 8) and on d 43, 64, 92, 120, and before slaughter (d 167) for follow-up of hematocrit of calves. Hematocrit was defined as the volume of packed red blood cells divided by the total volume of blood sample.

\section{Statistical Analysis}

Fixed linear models were used to analyze the data (Proc GLM, SAS 9.1; SAS Institute Inc., Cary, NC). The models included the effects of diet for each of the 6 BW (d 8, 43, 64, 92, 120, and 167), cold carcass weight (d 168), ADG (d 8 to 92; d 92 to 168; d 8 to 168), feed intake (d 8 to 92 ; d 92 to 168 ; d 8 to 168), and FCR (d 8 to 92 ; d 92 to 168 ; d 8 to 168 ).

They included the effects of diet, day, and the interaction between diet and day for total SCFA, acetate, propionate, and butyrate concentrations. Fisher's exact tests (Proc FREQ, SAS 9.1; SAS Institute Inc.) were used to analyze the effects of diet on the carcass characteristics (color and conformation). A probability level of $P<0.05$ was considered statistically significant, and $P<0.10$ was considered a tendency.

\section{RESULTS AND DISCUSSION}

The objectives of this work were to evaluate the effects of 2 different daily doses of scFOS added to a CMR containing soluble wheat proteins on growth performance, carcass characteristics, and fecal concentrations of SCFA of preruminant veal calves.

During the growing and finishing periods, ADG and FCR were similar between groups of animals. Feed intake increased with the age of the animals but was not affected by treatment (Table 2).

In the control group, considering the entire period, the ADG was approximately $1.15 \mathrm{~kg}$, leading to a final BW of approximately $235 \mathrm{~kg}$ and a carcass weight of $131 \mathrm{~kg}$. These growth performances are consistent with what is usually observed in Prim' Holstein veal calves fed skim milk (Labussiere et al., 2008; Legrand et al., 2010). The CMR used in the present study did not contain skim milk but was composed of whey, whey protein concentrate, and approximately $5 \%$ soluble wheat proteins. Unlike soybean, potato, or fish proteins, which may negatively affect ADG when they replace milk protein (Seegraber and Morrill, 1986; Silva et al., 1986; Troccon and Toullec, 1989), the inclusion of wheat protein up to $19 \%$ of total CMR proteins did not seem to alter the growth performance of preruminant calves, measured as final BW, feed intake, or ADG (Toullec and Grongnet, 1990; Ortigues-Marty et al., 2003). Mortality was low during the entire study in every group of animals, and no particular event, such as diarrhea or respiratory disease, appeared (data not shown).

Supplementation of the CMR with 3 and $6 \mathrm{~g} / \mathrm{d}$ induced, respectively, nonsignificant increases of 3.2 and $4.8 \mathrm{~kg}$ of BW when recorded just before slaughtering at d 167 (Table 2). Regarding BW, a dose-effect relationship seemed be observed in favor of the highest dosage of the prebiotic ingredient: during the finishing period, the BW of calves receiving $6 \mathrm{~g} / \mathrm{d}$ was higher than that of calves receiving $3 \mathrm{~g} / \mathrm{d}$. Overall, the FCR was decreased more with 6 than $3 \mathrm{~g} / \mathrm{d}$ of scFOS, 5 and 3 points less, respectively, compared with the control diet when the entire period was considered $(P=0.10$, Table 2$)$. These observations are consistent with previous observations in a veal calf study (Beghin Meiji, unpublished data); $6 \mathrm{~g} / \mathrm{d}$ of scFOS tended to allow better growth performance than did $3 \mathrm{~g} / \mathrm{d}$.

In other animal species, a dose-effect relationship between scFOS dosages and an improvement in growth performance are generally observed. In tilapia, the effects of 2 dosages of scFOS on the specific growth rate and FCR were compared with a control diet; the lower 
Table 2. Effect of the short-chain fructooligosaccharide (scFOS) diet on the performances of veal calves ${ }^{1}$

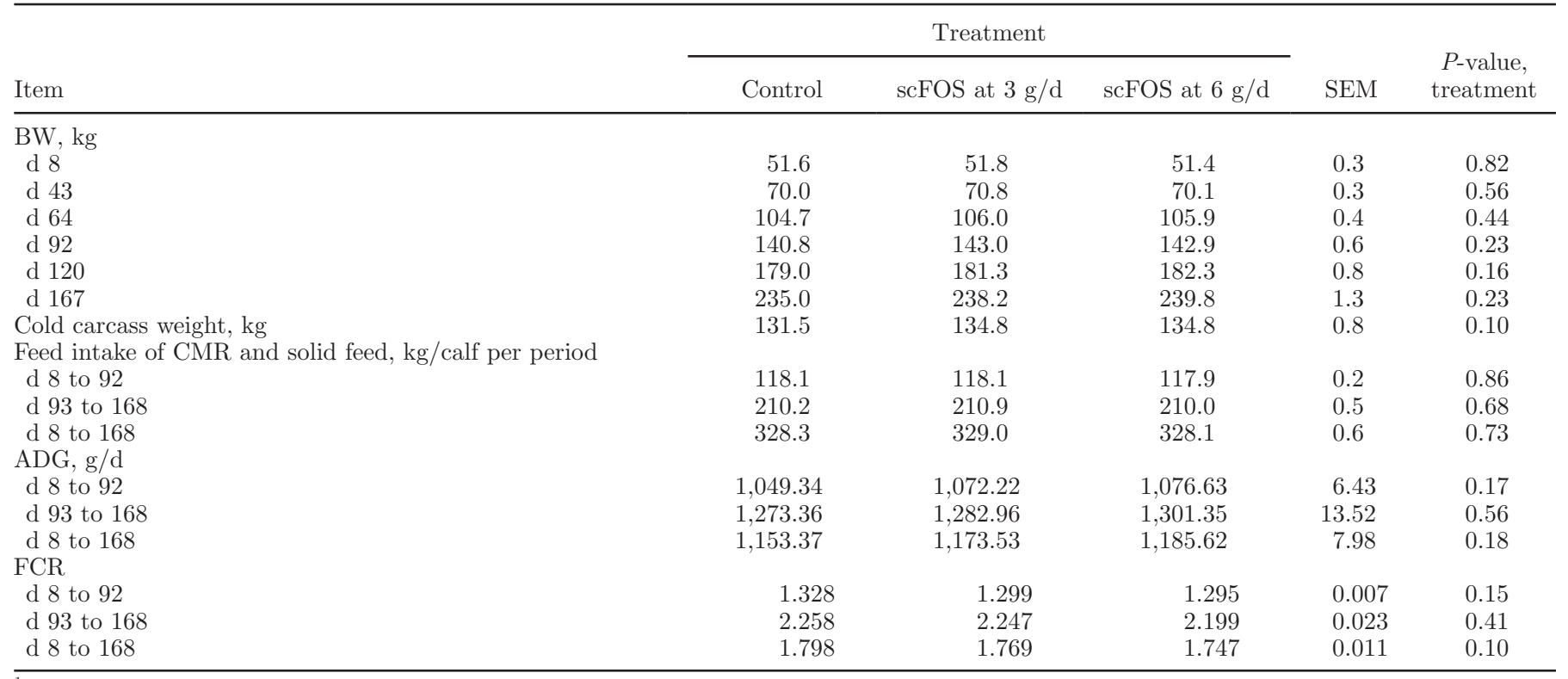

${ }^{1} \mathrm{SEM}=$ pooled $\mathrm{SEM} ; \mathrm{CMR}=$ calf milk replacer; FCR $=$ feed conversion ratio.

dosage did not induce significant changes, unlike the higher one (Lv et al., 2007). In broilers, in comparison with a control diet, 3 dosages of scFOS were tested, and they allowed an improvement in growth performance measures such as ADG and FCR; however, the best improvement was obtained with an intermediate level of the prebiotic ingredient (Xu et al., 2003). From the results of these 2 studies, the correlation between dosage and improvement does not seem to be linear; an optimal dosage of scFOS may improve the growth performance of animals.

Cold carcasses from calves supplemented with scFOS weighed $3.3 \mathrm{~kg}$ more than did carcasses from the control animals (Table 2; $P=0.10$ ), with no dose-effect relationship between the 2 daily doses. The fact that the cold carcass weights of animals fed $6 \mathrm{~g} / \mathrm{d}$ of scFOS were higher than the carcass weights of animals receiving $3 \mathrm{~g} / \mathrm{d}$ even though the live weights of the animals from these 2 groups were similar may be explained by an increase in the weight of the intestines of animals receiving the high dosage of prebiotic. In piglets, scFOS increased the villus height and crypt depth of the large intestine (Howard et al., 1995; Spencer et al., 1997; Tsukahara et al., 2003). Thus, it can easily be hypothesized that the same improvement in mucosal structure occurs in veal calves, leading to a greater intestinal weight. It was also demonstrated that scFOS increased the total anaerobic microbial population in horses (Respondek et al., 2008) and in veal calves, in an in vitro trial using ileal effluent (Philippeau et al., 2010), which may also help explain the greater intestinal weight.
In the present study, carcass characteristics, such as color and conformation, were not different in the 3 groups of animals (Table 3 ). The absence of an effect of scFOS on the color of meat was confirmed by the hematocrit level of calves, which was similar among the groups (average hematocrit: $22.7 \pm 2.6 \%$ at $d 167$ ), and it matched the objective to obtain a light-colored meat. The fatness of the carcass was quite similar in the 3 groups of animals (average score of 3 assigned). The conformation and degree of fatness of the carcass were equivalent among the groups, whereas the carcasses from supplemented animals weighed $3.3 \mathrm{~kg}$ more; thus, we can hypothesize that the additional carcass weight from animals receiving scFOS was not constituted by fat, but rather by muscle mass.

The effects of dietary supplementation of veal calves with scFOS have not been studied extensively. In the first published study on the growth performance of preruminant calves (Kaufhold et al., 2000), 10-wk-old Prim'Holstein calves were supplemented or not supplemented with $10 \mathrm{~g} / \mathrm{d}$ of scFOS in their CMR for $3 \mathrm{wk}$. Even though the design and the quantity of scFOS ingested per day between the present study and the study by Kaufhold et al. (2000) are not really comparable, the authors similarly observed that scFOS tended to increase the BW of the animals. Another study with a design closer to the present study showed that in comparison with a CMR containing antibiotics, the supplementation of male Prim'Holstein calves with 3 $\mathrm{g} / \mathrm{d}$ of scFOS for $140 \mathrm{~d}$ allowed a significant increase in $\mathrm{BW}$ at the end of the study and improvements in $\mathrm{ADG}$ 
Table 3. Effect of short-chain fructooligosaccharides (scFOS) on carcass characteristics of calves at slaughter $(169 \mathrm{~d} \text { old })^{1}$

\begin{tabular}{lcccc}
\hline & \multicolumn{3}{c}{ Treatment } \\
\cline { 2 - 3 } Carcass characteristic & Control & scFOS at 3 g/d & scFOS at 6 g/d & SEM \\
\hline Color $^{2}$ & 2.17 & 2.21 & 2.19 & 0.03 \\
Conformation & & 7.57 & 7.57 & 0.07 \\
\hline${ }^{1} \mathrm{SEM}=$ pooled SEM. & 7.37 & & \\
${ }^{2}$ The color carcass scale ranged from 1 (white) to 4 (red). \\
${ }^{3}$ Conformation was evaluated by the EUROP standard (E = excellent, P = degraded conformation, with inter- \\
mediate levels of classification). Numerical values were assigned to the conformation observed: carcasses that \\
were scored U obtained a grade of 15, and carcasses that scored P had a grade of 4, with intermediate grades.
\end{tabular}

and FCR (Veissier et al., 2003), thus confirming the results observed in the present study.

The fecal concentration of total SCFA increased with time $(P=0.03$; Table 4$)$, but no effect of the dietary supplementation was observed with scFOS. The proportion of acetate increased with time, whereas the proportion of propionate decreased $(P<0.01)$. The treatment tended to favorably affect the butyrate proportion, whereas scFOS supplementation reduced the proportion of acetate. Thus, the inclusion of scFOS in the CMR seemed to induce a shift in the fecal microbial metabolism from acetate to butyrate because of the ingestion of scFOS. No interaction between time and treatment was observed whatever the SCFA considered.

With these percentages, a ratio reflecting the proportion of each SCFA, acetate:propionate:butyrate, could be defined. In this study, it was equal to approximately $55: 34: 11$ at $\mathrm{d} 36$.

In a similar study in veal calves, SCFA concentrations were also determined in the feces of veal calves at approximately $35 \mathrm{~d}$ of age, and the same ratio was 67:23:10 (Fisher, 2011), similar to ours. Similar to the report by Fisher (2011) and in the review by Bergman (1990), who reported an average ratio between 75:15:10 and 40:40:20, we also showed that acetate was predominant in feces, followed by propionate and then butyrate, which was not the case in the study by Cannon (2009). Acetate was also predominant but was followed by butyrate and then propionate (a ratio of 60:17:23).

The difference observed between the ratio of Cannon (2009) and others may be explained by the age of the animals at sampling and by the origin of the samples. Short-chain FA were determined in digesta from the distal colon of 28-d-old male Holstein calves in the study by Cannon (2009), but this may be also explained by the feed provided to the veal calves. In our study and that by Fisher (2011), animals were fed a CMR and solid feed (in the form of cereal-based pellets), whereas in the study by Cannon (2009), animals were fed only CMR. Thus, we can hypothesize that the inclusion of

Table 4. Effect of short-chain fructooligosaccharides (scFOS) on total short-chain FA (SCFA) concentrations and on percentage of main SCFA in the feces of veal calves ${ }^{1}$

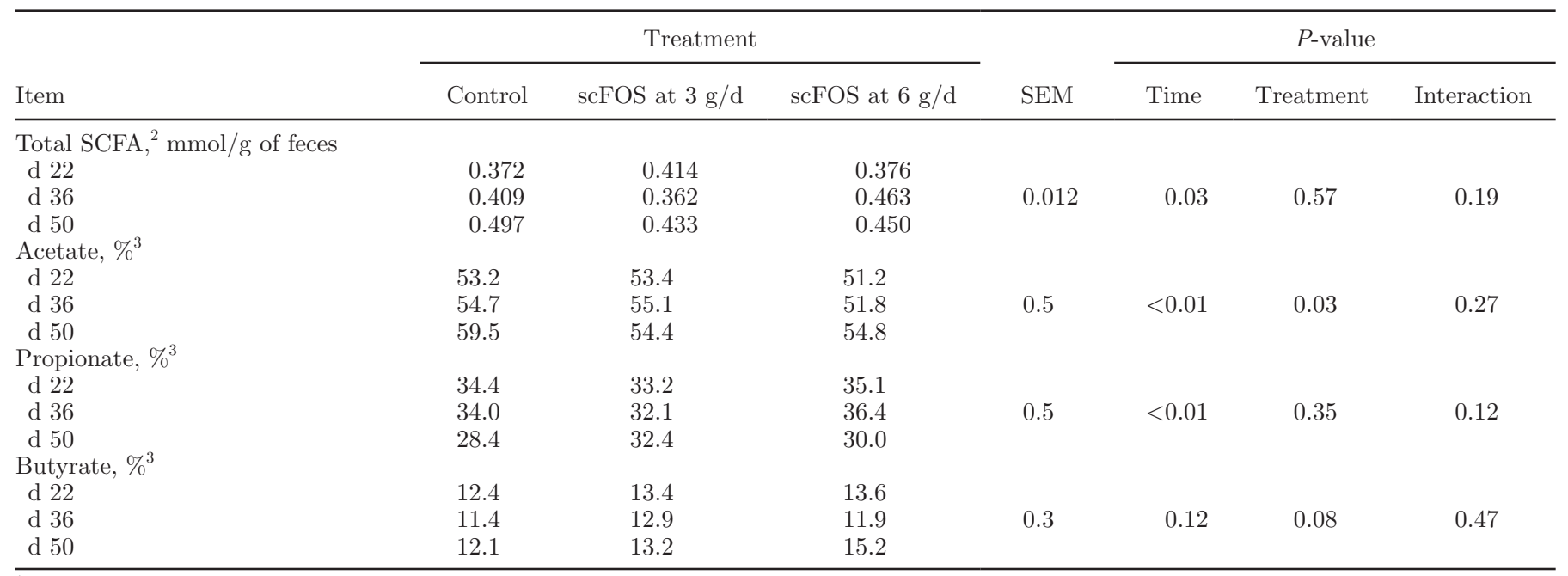

${ }^{1} \mathrm{SEM}=$ pooled SEM.

${ }^{2}$ Total SCFA = acetate, propionate, butyrate, isobutyrate, valerate, and isovalerate.

${ }^{3}$ Percentage of acetate means quantity of acetate divided by the sum of (acetate + propionate + butyrate). 
cereals in the diet of animals modified the fermentative metabolism by bacteria present in the intestine of veal calves and particularly affected the metabolism of propionate and butyrate.

Only 1 study has been published on the effects of scFOS on the concentrations of SCFA in the digestive content of veal calves. This was an in vitro study in which ileal contents of veal calves were collected at slaughter, pooled from 5 animals, and incubated for $24 \mathrm{~h}$ with a substrate containing or not containing scFOS. During this in vitro fermentation, total SCFA concentration and, more particularly, acetate proportion were increased in comparison with a control fermentation substrate without scFOS (Philippeau et al., 2010). In the present study, SCFA concentrations were determined in feces collected directly from the rectum and showed a decrease in acetate proportion and an increase in butyrate proportion, without a marked effect on propionate. According to Campbell et al. (1997) and $\mathrm{Xu}$ et al. (2005), the concentrations of SCFA in cecal and fecal contents are not correlated. This may explain the differences observed between the present study and the one by Philippeau et al. (2010). Furthermore, our results were obtained in vivo, whereas those by Philippeau et al. (2010) were obtained in vitro. These methods of sampling and of analysis could explain some differences observed in the evolution of SCFA. In addition, for technical reasons, we had no samples of feces before the beginning of supplementation in the present study (d 8), so the evolution of SCFA production was measured beginning after $14 \mathrm{~d}$ of supplementation.

It is well recognized that scFOS are fermented in the gut by most strains of Bifidobacterium and by certain strains of Lactobacillus that, in turn, produce lactate and SCFA (Kaplan and Hutkins, 2000; Cummings and Macfarlane, 2002; Rossi et al., 2005; Saulnier et al., 2007).

It has been established that SCFA, and particularly butyrate, are the main energy source for cells of the large intestine, allowing an improvement in its epithelial structure (Bergman, 1990; Scheppach, 1994). The increase in butyrate reported in the present study may induce an improvement in the mucosal structure of animals, as demonstrated in piglets supplemented with scFOS (Tsukahara et al., 2003). Recently, it was shown that a diet enriched with scFOS increased the density of FFA receptor 2 (FFA2, formerly GPR43) in the proximal colon of rats (Kaji et al., 2011). These concomitant increases in SCFA concentrations, and more specifically butyrate, and their specific receptors in the colon linked to the consumption of scFOS could explain the observed effects on epithelial structure.

Furthermore, scFOS fermentation by lactic acid bacteria produces lactate (Saulnier et al., 2007), which can be used by a strain of bacteria, Megasphaera elsdenii, the main lactate-utilizing bacteria in the rumen of cattle. Thus, the SCFA concentration increases via the direct fermentation of scFOS, and also by the conversion of lactate by some acid-utilizing bacteria, such as M. elsdenii (Tsukahara et al., 2002; Hashizume et al., 2003).

In our study, by increasing the SCFA production, the crypt depth and the villus height of the large intestine of preruminant calves may have been increased. Some digestives enzymes are found in the brush border of the small intestine; these are not free in the lumen of the intestine but are attached in the membrane of enterocytes. Thus, by increasing the crypt depth and villus height, scFOS participates in increasing the membrane surface in the large intestine and, perhaps to a lesser extent in the small intestine, potentially inducing an increase in enzymes that are linked (disaccharides and peptidases). Consequently, more disaccharides and peptides could be broken down and then absorbed in the small intestine. However, the effects of scFOS on apparent digestibility are inconsistent. In some studies, the digestibility was not affected when scFOS were added in the diets of dogs (Swanson et al., 2002a,b; Flickinger et al., 2003), whereas in other studies using dogs and weaned pigs, the digestibility was increased (Russel et al., 1998; Howard et al., 2000; Barry et al., 2009).

Energy can also be provided by SCFA that are produced by microbial fermentation of some carbohydrates in the intestine (Kaplan and Hutkins, 2000; Cummings and Macfarlane, 2002; Rossi et al., 2005; Saulnier et al., 2007). According to Bergman (1990), SCFA could contribute up to $70 \%$ of the caloric requirements of ruminants. The energy supplied by the catabolism of SCFA can ensure the basic metabolic requirements, and the remaining energy could be used for growth of the animal.

\section{CONCLUSIONS}

The use of CMR containing wheat proteins and supplemented with scFOS during the entire rearing period of veal calves allowed a reduction in the FCR with a dose-effect relationship and an increase in the carcass weight of animals at slaughter. Some changes in SCFA production were observed in this study; the supplementation seemed to induce a shift in fecal microbial metabolism from acetate to butyrate. Under the conditions of the present study, inclusion of scFOS in the CMR tended to enhance some growth parameters of preruminant calves.

\section{ACKNOWLEDGMENTS}

Beghin Meiji (Marckolsheim, France) sponsored the study. 


\section{REFERENCES}

Barry, K. A., D. C. Hernot, I. S. Middelbos, C. Francis, B. Dunsford, K. S. Swanson, and G. C. Fahey Jr. 2009. Low-level fructan supplementation of dogs enhances nutrient digestion and modifies stool metabolite concentrations, but does not alter fecal microbiota populations. J. Anim. Sci. 87:3244-3252.

Bergman, E. N. 1990. Energy contributions of volatile fatty acids from the gastrointestinal tract in various species. Physiol. Rev. 70:567-590.

Bunce, T. J., M. D. Howard, M. S. Kerley, and G. L. Allee. 1995. Feeding fructooligosaccharides to calves increased bifidobacteria and reduced Escherichia coli. J. Anim. Sci. 73(Suppl. 1):281. (Abstr.)

Campbell, J. M., G. C. Fahey Jr., and B. W. Wolf. 1997. Selected indigestible oligosaccharides affect large bowel mass, cecal and fecal short-chain fatty acids, $\mathrm{pH}$ and microflora in rats. J. Nutr. 127:130-136.

Cannon, S. J. 2009. Effects of psyllium in milk replacers for neonatal dairy calves. MS Thesis. University of Illinois, Urbana-Champaign.

Cummings, J. H., and G. T. Macfarlane. 2002. Gastrointestinal effects of prebiotics. Br. J. Nutr. 87(Suppl. 2):S145-S151.

Fisher, B. L. 2011. Effects of resistant starch in milk replacer on health and performance of neonatal Holstein heifer calves. MS Thesis. Louisiana State University, Baton Rouge.

Flickinger, E. A., E. M. Schreijen, A. R. Patil, H. S. Hussein, N. R. Merchen, and G. C. Fahey Jr. 2003. Nutrient digestibilities, microbial populations, and protein catabolites as affected by fructan supplementation of dog diets. J. Anim. Sci. 81:2008-2018.

Gibson, G. R., H. Probert, J. van Loo, R. A. Rastall, and M. B. Roberfroid. 2004. Dietary modulation of the human colonic microbiota: Updating the concept of prebiotics. Nutr. Res. Rev. 17:259-275.

Hashizume, K., T. Tsukahara, K. Yamada, H. Koyama, and K. Ushida. 2003. Megasphera elsdenii JCM 1772 normalizes hyperlactate production in the large intestine of fructooligosaccharide-fed rats by stimulating butyrate production. J. Nutr. 133:3187-3190.

Howard, M. D., D. T. Gordon, L. W. Pace, K. A. Garleb, and M. S. Kerley. 1995. Effects of dietary supplementation with fructooligosaccharides on colonic microbiota populations and epithelial cell proliferation in neonatal pigs. J. Pediatr. Gastroenterol. Nutr. 21:297-303.

Howard, M. D., M. S. Kerley, G. Sunvold, and G. Reinhart. 2000. Source of dietary fiber fed to dogs affects nitrogen and energy metabolism and intestinal microflora populations. Nutr. Res. 20:1473-1484.

Howard, M. D., H. Liu, J. D. Spencer, M. S. Kerley, and G. L. Allee. 1999. Incorporation of short-chain fructooligosaccharides and Tylan into diets of early-weaned pigs. Pages $90-95$ in UMC Anim. Sci. Dept. Rep. University of Missouri, Columbia.

Jouany, J. 1982. Volatile fatty acids and alcohol determination in digestive content, silage juices, bacterial cultures and anaerobic fermentation contents. Sci. Alim. 2:131-144.

Kaji, I., S. Karaki, R. Tanaka, and A. Kuwahara. 2011. Density distribution of free fatty acid receptor 2 (FFA2)-expressing and GLP-1-producing enteroendocrine L cells in human and rat lower intestine, and increased cell numbers after ingestion of fructo-oligosaccharide. J. Mol. Histol. 42:27-38.

Kaplan, H., and R. Hutkins. 2000. Fermentation of fructooligosaccharides by lactic acid bacteria and bifidobacteria. Appl. Environ. Microbiol. 66:2682-2684.

Kaufhold, J. N., H. M. Hammon, and J. W. Blum. 2000. Fructooligosaccharide supplementation: Effects on metabolic, endocrine and hematological traits in veal calves. J. Vet. Med. A 47:17-29.

Labussiere, E., S. Dubois, J. van Milgen, G. Bertrand, and J. Noblet. 2008. Effects of dietary crude protein on protein and fat deposition in milk-fed veal calves. J. Dairy Sci. 91:4741-4754.

Legrand, I., C. Martineau, G. Bertrand, F. Gautier, and T. Lefebvre. 2010. Production et caractérisation des veaux de boucherie de 6 mois, de 8 mois et d'animaux plus âgés produits en France. Renc. Rech. Rumin. 17:369-372.

Lv, H.-Y., Z.-g. Zhou, F. Rudeaux, and F. Respondek. 2007. Effects of dietary short-chain fructo-oligosaccharides on intestinal microflo- ra, mortality and growth performance of $O$. aureus $\times$ O. niloticus . Chin. J. Anim. Nutr. 19:1-6.

Ofival. 1976. Grille de classement des carcasses de veau. Accessed May 31, 2010. http://www.office-elevage.fr/publications/classement/ veaux.pdf

Ortigues-Marty, I., J. Hocquette, G. Bertrand, C. Martineau, M. Vermorel, and R. Toullec. 2003. The incorporation of solubilized wheat proteins in milk replacers for veal calves: Effects on growth performance and muscle oxidative capacity. Reprod. Nutr. Dev. 43:57-76.

Philippeau, C., F. Respondek, and V. Julliand. 2010. In vitro effects of fructo-oligosaccharides on bacterial concentration and fermentation profiles in veal calf ileal contents. Anim. Feed Sci. Technol. 162:83-90.

Respondek, F., A. G. Goachet, and V. Julliand. 2008. Effects of dietary short-chain fructo-oligosaccharides on the intestinal microflora of horses subjected to a sudden change in diet. J. Anim. Sci. 86:316-323.

Roberfroid, M. B., G. R. Gibson, L. Hoyles, A. L. McCartney, R. A. Rastall, I. R. Rowland, D. Wolvers, B. Watzl, H. Szajewska, B. Stahl, F. Guarner, F. Respondek, K. Whelan, V. Coxam, M. J. Davicco, L. Leotoing, Y. Witrant, N. M. Delzenne, P. D. Cani, A. M. Neyrinck, and A. Meheust. 2010. Prebiotic effects: Metabolic and health benefits. Brit. J. Nutr. 104(Suppl. 2):1-149.

Rossi, M., C. Corradini, A. Amaretti, M. Nicolini, A. Pompei, S. Zanoni, and D. Matteuzi. 2005. Fermentation of fructooligosaccharides and inulin by bifidobacteria: A comparative study of pure and fecal cultures. Appl. Environ. Microbiol. 71:6150-6158.

Russel, T., M. Kerley, G. Allee, and M. Howard. 1998. Fructooligosaccharides improve nitrogen metabolism and reduces fecal excretion of odor metabolites in the weaned pig. Animal Sciences Department, University of Missouri, Columbia

Saulnier, D. M. A., D. Molenaar, W. M. de Vos, G. R. Gibson, and S Kolida. 2007. Identification of prebiotic fructooligosaccharide metabolism in Lactobacillus plantarum WCFS1 through microarrays. Appl. Environ. Microbiol. 73:1753-1765.

Scheppach, W. 1994. Effects of short chain fatty acids on gut morphology and function. Gut 35:S35-S38.

Seegraber, F. J., and J. L. Morrill. 1986. Effect of protein source in calf milk replacers on morphology and absorptive ability of small intestine. J. Dairy Sci. 69:460-469.

Silva, A. G., J. T. Huber, and R. M. DeGregorio. 1986. Influence of substituting two types of soybean protein for milk protein on gain and utilization of milk replacers in calves. J. Dairy Sci. 69:172180.

Spencer, J. D., K. J. Touchette, H. Liu, G. L. Allee, M. D. Newcomb, M. S. Kerley, and L. W. Pace. 1997. Effect of spray-dried plasma and fructooligosaccharides on nursery performance and small intestinal morphology of weaned pigs. J. Anim. Sci. 75(Suppl. 1):199. (Abstr.)

Swanson, K. S., C. M. Grieshop, E. A. Flickinger, L. L. Bauer, J. Chow, B. W. Wolf, K. A. Garleb, and G. C. Fahey Jr. 2002a. Fructooligosaccharides and Lactobacillus acidophilus modify gut microbial populations, total tract digestibilities and fecal protein catabolite in healthy adult dogs. J. Nutr. 132:3721-3731.

Swanson, K. S., C. M. Grieshop, E. A. Flickinger, L. L. Bauer, H. P. Healy, K. A. Dawson, N. R. Merchen, and G. C. Fahey Jr. 2002b. Supplemental fructooligosaccharides and mannanoligosaccharides influence immune function, ileal and tract nutrient digestibilities, microbial populations and concentrations of protein catabolites in the large bowel of dogs. J. Nutr. 132:980-989.

Toullec, R., and J. F. Grongnet. 1990. Remplacement partiel des protéines du lait par celles du blé ou du maïs dans les aliments d'allaitement: Influence sur l'utilisation digestive chez le veau de boucherie. INRA Prod. Anim. 3:201-206.

Troccon, J. L., and R. Toullec. 1989. Aliments d'allaitement pour veaux d'élevage. Remplacement de la poudre de lait écrémé par d'autres sources protéiques. INRA Prod. Anim. 2:117-128.

Tsukahara, T., Y. Iwasaki, K. Nakayama, and K. Ushida. 2003. Stimulation of butyrate production in the large intestine of weaning piglets by dietary fructooligosaccharides and its influence on the 
histological variables of the large intestinal mucosa. J. Nutr. Sci. Vitaminol. (Tokyo) 49:414-421.

Tsukahara, T., K. Koyama, M. Okada, and K. Ushida. 2002. Stimulation of butyrate production by gluconic acid in pig cecal digesta and identification of butyrate producing bacteria. J. Nutr. 132:2229-2234.

Veissier, I., G. Bertrand, and R. Toullec. 2003. Le veau de boucherie: Concilier bien-être animal et production. INRA, Paris, France.
Xu, C., X. Chen, C. Ji, Q. Ma, and K. Hao. 2005. Study of the application of fructo-oligosaccharides in piglets. Asian-australas. J. Anim. Sci. 18:1011-1016.

Xu, Z. R., C. H. Hu, M. S. Xia, X. A. Zhan, and M. Q. Wang. 2003. Effects of dietary fructooligosaccharides on digestive enzyme activities, intestinal microflora and morphology of male broilers. Poult. Sci. 82:1030-1036. 